East African Medical Journal Vol. 80 No.7 July 2003

UNUSUAL BLADDER OUTFLOW OBSTRUCTION: CASE REPORT

P.L.W. Ndaguatha, MBChB, MMed (Surg), Senior Lecturer, Department of Surgery, College of Health Sciences, University of Nairobi, P.O. Box 19676, Nairobi, Kenya

\title{
UNUSUAL BLADDER OUTFLOW OBSTRUCTION: CASE REROPT
}

\author{
P.L.W. NDAGUATHA
}

\section{SUMMARY}

\begin{abstract}
Hydatid disease, the parasitic infestation caused by the cestode, echinococcus granulosus involves mainly the liver and the lungs though no organ is immune. Genito urinary involvement has been found mainly in the kidneys and rarely in other structures such as, bladder and epididymis. Isolated retrovesical location of the hydatid cyst is a very rare condition whose manifestations appears after a long course of the disease and are due to compression of bladder, causing the bladder out flow obstruction. Such rare case of bladder out flow obstruction is presented.
\end{abstract}

\section{INTRODUCTION}

The usual causes of urinary retention in young adults are thought to be mainly due to urethral strictures, acute urethritis or prostatitis, balonoposthitis in the uncircumcised, traumatic urethral ruptures, whereas prostatic enlargements in the old are the commonest. When the above are not quite obvious, then it is important to think of other causes of the urinary retentions that may be otherwise very remote. It is with the above in mind that the unusual case of the bladder outflow obstruction due to pelvic retrovesical hydatid cyst is herein reported in a young man who had otherwise ill defined cause of the repeated urinary retention.

Hydatid disease or echinococcosis is a cyclozoonotic parasitic infestation caused by the cestode, the echinococcus granulosus that involves the liver and the lungs mainly although no organ is immune. The disease is endemic in the sheep and cattle rearing countries such as Australia, New Zealand, South Africa, Asia, Southern Europe, Middle East and also mainly in East Africa. In Kenya, human hydatidosis is reported to be high in Turkana District and this has been reported as probably the highest incidence in the world (1). Areas in Kenya, outside the pastoral communities that were thought to be immune of the disease have in the past reported sporadic cases (2).

\section{CASE REPORT}

KOS was a 31-year old male who presented to Kikuyu Mission Hospital on April 1992 with a history of inability to pass urine, where in was catheterised and had this indwelling self retaining catheter for two weeks before it being removed. He was able to pass urine there after but retained again after only two days and again went back to the same hospital and re- catheterised with a non-dwelling catheter. Apparently, though not clear, the patient went home but resurfaced to a nursing home on 29th May 1992 with the complaints of abdominal pains for one month and two days history of urinary retention. Generally, he was found to be pyretic, temperature of $38.5^{\circ}$ centigrade and somewhat a bit confused. Examination of the abdomen showed mild distension, and a soft tender mass in the left groin and supra pubic region. It was not possible to discern its margins despite being catheterised. Rectal examination did not reveal enlarged prostate though a suspicious mass was felt bimanually between the bladder and the rectum. Laboratory work up showed: BUN of $35 \mathrm{mg} \%$, Na $139 \mathrm{mEq} / \mathrm{L}, \mathrm{K} 4.4 \mathrm{mEq} / \mathrm{L}$, Haemogram $15.5 \mathrm{~g} / \mathrm{dI}$, and normal peripheral smear.

HIV test done was negative. The ultrasonographic test that was ordered showed a large multicystic mass lying in the inferior aspect of the bladder. This necessitated the ordering of an IVU that showed an intrinsic multiseptate bladder growth suggesting the possibility of bladder hydatid cyst. The casoni's test was hence requested but the results were not available. The surgeon who initially saw the patient decided to seek the urosurgical opinion for further management. Re-evaluation of the U/S and IVU films were done, and at the physical abdominal examination, a suprapubic mass mainly on left side was felt. Per rectum, a mass about $6 \mathrm{~cm}$ from the anal verge was felt extending into the rectovesical space and narrowing the rectal lumen, a mucoid material on the examination finger was evident. Barium enema was hence ordered to rule out the rectal mass. It showed instead an extrinsic mass compressing the rectum. The patient was updated on his condition and was advised to undergo the cystoscopy in well set up hospital where facilities were available in order to delineate the mass, whether it was intravesical or if there was any recto vesical fistula. Since the earlier results of the casoni's test requested were not readily available, the repeat one was contemplated but the patient declined. More over the patient did not wish to await any further investigations or any trial of medical treatments, and insisted on surgical intervention. 


\section{Figure 1}

Kidney, ureter and bladder plain film

Figure 2

Intravenous urogram

Figure 3

Barium enema

The patient underwent exploratory laparatomy six days after admission. The lower midline sub-umbilical incision was made. All the visceral areas inspected were normal except for the firm mass that was identified within the bladder wall extending postero-laterally to compress the rectum. The mass also seemed to compress the bladder into a small sac. As the margins were not clear, cystostomy was done and a normal urinary cavity, save for the small size was evident. Bimanual exploration (one hand intravesically and the other extravesically), the mass was thought to be intramural, pushing the bladder to the right side of the pelvis and also extending to the rectum. The formalin soaked swabs or mops were secured and the excision of the mass in toto was attempted despite the firm adherence to the bladder wall and the rectum. Towards the end of the excision, the cyst ruptured and the milky fluid laden with multiple daughter cysts was sucked, leaving the empty sac (endocyst and ectocyst linings). As the excision of this empty sac wall continued, it was found to be merging with the rectal wall, hence careful dissection off the rectal wall was done but perforation of the rectum inadvertently occurred. This rent was repaired in layers using 00 vicryl after formalin wash, followed by the fashioning of the loop colostomy proximally. After being informed of the procedures performed, he was postoperatively started on albendazole.

The microscopy of the cyst fluid was said to contain the multiple embryonal scolices (hydatid sand) but the histology of the cyst wall was reported as containing the fibrous lining; there was no mention of typical features of hydatidosis. On the 5th day postoperatively, it was noticed that there was mild faeculent/ purulent leakage via the drainage site. The dressings were done daily and stopped on 8th postoperative day after the sinus closed. Repeat barium enema three months later showed a normal flow of the dye upto the colostomy site. The closure of the colostomy was done there after, and follow up was done upto the end of 2001 when he was discharged as he did not have any complaints.

\section{DISCUSSION}

Man is the intermediate host of the tape worm; echinococcus granulosus. In the definitive host (dog, cat, fox or the wolf), adult worm inhabit the intestinal mucosa and when the ova of the parasites are discharged via the faeces, the intermediate host (man, sheep and cattle) become infested by ingesting the ova. The cycle is completed when the contaminated carcass of the intermediate host is eaten by the definitive host. The manifestations of the disease in the intermediate host occur when the larvae hatch out in the duodenum and penetrate the intestinal wall and via the portal system, are transported to the liver and other parts of the body via the blood stream. The involvement of the genito-urinary system is almost always renal although sporadic cases involving the urinary bladder, prostate, epididymis have been reported (3).

Studies in Saudi Arabia have shown the incidence of genito-urinary involvement to be $6.4 \%$ of all reported cases. Isolated retrovesical location of the hydatid cyst is a very uncommon condition and the clinical pattern appears after a long course of the cyst. They are represented by hypogastric mass associated with compressive manifestations of the adjacent organs, i.e. bladder or the rectum. In case of the bladder, it may be so compressed that obstructive features appear as in this case being reported and elsewhere (4). Localisation and diagnosis of retrovesical hydatid cyst may be made by employing U/S, but in cases of bladder outflow obstruction, the diagnosis may be delayed because the cysts, if univesicular, may be mistaken repeatedly for the distended bladder on U/S (5). Our patient though had similar presentation did not pose any difficulties in diagnosis on U/S. When the diagnosis is unclear, then CT Scan can be used to localise the pelvic cysts that are established by anatomical criteria.

Occasionally the transverse plane can be confusing 
for the precise localisation of the lesion. The appearance of a central location close to the boundaries of the bladder and rectum can define peritoneal location, and further posterolateral retrovesical location can be considered retroperitoneal (6).

The cysts in relation to the urinary bladder are treated by the removal of the laminated membrane i.e., cystectomy and pericystic resection as extensive as possible for any successful results to be realised (7). There are isolated reports in the literature that surgical excisions have been effective in alleviation of the symptoms and improving the renal function in those patients with pelvic hydatid cyst presenting with obstructive uropathy and renal failure (8). Since these large cysts are densely adherent to the pelvic wall as well as the bladder, the complete dissections are harzadous. The attendant morbidity may result as in our case where the rectum was inadvertently perforated necessitating the repair and fashioning of the colostomy. To avoid the above morbidity, it is advisable to plicate the adventitious membrane and give postoperative albenzole in order to reduce the risk of implantation of the scolices $(9,10)$. Where severe obstructive uropathy is present, one can either insert the ureteric J.J. stent if the ureteric orifices are not obscured by the compressed bladder due to huge pelvic hydatid cysts. If the urinary bladder is so compressed, then percutaneous nephrostomy, employing the posterior tract should be performed.

Where Hydatid cyst of the bladder wall is found to be communicating with bladder lumen, a non-operative management may be used. The intravescical instillation of $20 \%$ saline to destroy the germinal layer of the hydatid cyst-bladder fistula. That this is helpful has been shown with the consequent reduction of the pressure effects of the bladder as the evacuation of the daughter cysts via the urethra occur after the instillation of scolecidal agents; the sealing of the cyst-bladder communication has also been seen to occur as evidenced cystoscopically (11).

\section{REFERENCES}

1 French, C.M. Hydatid disease in the Turkana Region of Kenya. A study in medical geography. Ann. Trop. Med. Parasit., 1982; 76: 439.

2. Okelo, G.B.A. and Kyobe, J. A three year review of human hydatid disease seen at Kenyatta National Hospital. East. Afr. Med. J., 1976; 53: 540.

3. Buckley, R.J. Echinococcal disease of the kidney presenting as a renal filling defect. J. Urol., 1985; 133: 660-661.

4. Bahlman, J.C. Echinococcal cyst causing bladder outlet obstruction. A case report. S. Afr. Med. J., 1985; 70: 626-627.

5. Shetty, S.D. Hydatid disease of the urinary tract: evaluation of diagnostic methods. Brit. J. Urol., 1992. 69: 476-480

6. Kotoulas, G. Computed tomographic location of the pelvic hydatid disease. Eur. J. Radiology. 1990; 11: 38-41.

7. Moussaoui, A. et al., lsolated retrovesical hydatid cyst. J. Urol. 1994; 100: 101-104

8. Seem, V. Primary pelvic hydatid cyst presenting with obstructive uropathy and renal failure. Post Grad. Med. J. 1994; 70:930-932

9. Morris, A.L.et al., Albendazole-objective evidence of response in human hydatid disease. J. Amer. Med. Ass. 1986; 253: 2053 2057.

10. French, C.M. Membendazole and surgery for human hydatid disease in Turkana District, Kenya. East Afr. Med. J. 1984; 61:113-119.

11. Vaidyanathan, S. Non operative management of a pelvic hydatid cyst communicating with the bladder. J. Urol. 1979; 121: $245-271$. 